\title{
Reestruturação produtiva e novas formas de controle no local de trabalho: a experiência da indústria de fumo em Uberlândia-MG*
}

\author{
Productive restructuring and new control forms in the workplace: \\ the experience of the tobacco industry in Uberlândia-MG
}

\author{
Fabiane Santana Previtalli* \\ Andréia Farina de Faria***
}

RESUMO

O objetivo do trabalho é discutir a relação The objective of this paper to discuss the relaentre novas tecnologias e trabalho, tionship among new technologies and work, problematizando as diferentes dimensões entre problematizing the different dimensions among organização e controle do trabalho. Nosso foco organization and control of the work. Our focus consiste em analisar, a partir de um estudo de consists of analyzing, starting from a case study caso realizado no setor de fumo em accomplished in the section of tobacco in UberUberlândia/MG entre 2005-2007, até que lândia/MG among 2005-2007, how a group of ponto um conjunto de novas qualificações e new qualifications and abilities disputed by the habilidades demandadas pelas empresas está companies is implicating in a increase of implicando em maior autonomia do worker's autonomy in the factory ground and trabalhador no chão de fábrica e revertendo a reverting the extreme division among conceptextrema divisão entre concepção e execução do tion and execution of the work, pillar of the trabalho, pilar do padrão de acumulação pattern of accumulation taylorist-fordist or if, taylorista-fordista. Ou se, ao contrário, to the opposite, they potentiate, through new potencializam o controle do capital sobre o mechanisms, the control of the capital on the trabalho. Inicialmente consideramos o work. Initially we considered the work and of trabalho e a formação dos trabalhadores à luz the formation of the workers at the light of the da teoria marxista para, em seguida, Marxist theory for, soon afterwards, put in problematizamos a questão da ciência e da question the issue of the science and of the tecnologia como principal força produtiva. technology as main productive force, concluConcluímos com uma discussão sobre a ding with the discussion of the introduction of introdução das inovações na indústria de fumo. the innovations in the industry of tobacco.

PALAVRAS-CHAVE: trabalho, relações interfir- KEYWORDS: work, skills, tobacco production. mas, produção do fumo.

\footnotetext{
Este artigo corresponde a uma versão revisada e ampliada do trabalho: "Reestruturação Produtiva e Controle do Trabalho: o caso do setor de tabaco em Uberlândia/MG”, apresentado no V Colóquio Internacional Marx e Engels. Novembro de 2007.

$\mathrm{O}$ artigo visa divulgar resultados de pesquisas que estão sendo conduzidas no âmbito do Grupo de Pesquisa Trabalho, Educação e Sociedade, sob a coordenação da Profa. Dra. Fabiane Santana Previtalli (DECIS/FAFCS/UFU), com apoio da Fapemig.

Os autores agradecem as observações e sugestões à primeira versão deste artigo e assumem total responsabilidade pelo seu conteúdo.

** Doutora em Ciências Sociais, Professora da Universidade Federal de Uberlândia (UFU) / Brasil.

*** Mestranda em Ciências Sociais da Universidade Estadual Paulista Júlio de Mesquita Filho (UNESP/Araraquara). Bolsista Capes/ Brasil.
} 


\section{Introdução}

Nas últimas décadas observam-se transformações nas economias mundiais e um intenso processo de reestruturação produtiva do capital através da integração dos mercados financeiros. Estas mudanças estão fundamentadas no novo ideário político neoliberal de livre comércio e de uma menor presença do Estado como poder regulador das relações entre capital e trabalho. O conjunto desses elementos implica no retrocesso de conquistas sociais e caracteriza-se por um período de grandes perdas para a classe trabalhadora.

Sob a ótica do capital, cujo objetivo principal é a sua própria valorização, verifica-se um intenso processo de reorganização do trabalho com vistas à obtenção de maior flexibilidade e de elevação da produtividade, originando uma nova forma de controle do processo produtivo mediante a introdução de tecnologias de informação e práticas gerenciais, cujo discurso assenta-se na cooperação, no envolvimento e na parceria do trabalhador (PREVITALLI, 2006a; 2006b). Nesse novo contexto, onde a palavra de ordem passou a ser qualificação, as empresas observaram que muito do processo de inovação, particularmente as inovações incrementais no processo de trabalho, dependem da participação do trabalhador (BRESCIANI, 2001). Portanto, quanto mais motivado e envolvido com os objetivos da empresa, melhor adaptado estará às novas condições de concorrência no mercado. Essas transformações estão criando dificuldades para a ação dos sindicatos, reduzindo seu poder de representação junto à classe trabalhadora e, ao mesmo tempo, exigindo novas formas de articulação que viabilizem a incorporação, organização e representação dos novos segmentos de trabalhadores (ALVES, 2000; GALVÃO, 2006).

Vale dizer que a fábrica moderna nasceu mais da observação e apropriação do saber do artesão do que da incorporação do conhecimento científico à produção de mercadorias, como bem demonstra Marx (1988) na análise da transformação do trabalho artesanal até a grande indústria. Assim, o processo de reestruturação produtiva trás consigo novas formas de controle do trabalho. Ao desenvolver formas de cooptação do trabalhador por meio do compromisso com as metas das empresas, busca-se o controle sobre uma capacidade de produção subjetiva e sua aplicação ao processo de inovação com vistas ao aumento da produtividade e, em última instância, da valorização do capital. É 
nesse sentido que a problematização da relação entre trabalho e educação assume uma extrema relevância.

Nossa discussão parte de um estudo de caso no setor de fumo em Uberlândia/MG, em uma fábrica que a partir de agora denominaremos Fábrica Uberlândia que por sua vez, pertence a um grupo de destaque no setor, ao qual nos referiremos como Companhia Tabaco. ${ }^{1}$ Nessa etapa da pesquisa ${ }^{2}$ de campo, realizada entre março e novembro de 2007, sendo de 1995 a 2006 o período compreendido pela análise, foram entrevistados dois gerentes e três encarregados no local de trabalho. As questões, fechadas e semi-abertas, procuraram apreender o processo de reestruturação produtiva da empresa, a organização do processo de trabalho e as relações interfirmas, bem como as implicações das mudanças sobre os trabalhadores de chão-de-fábrica. Além das entrevistas, foram analisados documentos tais como informativos, revistas e apostilhas de programas de treinamento.

\section{Breves considerações sobre trabalho e formação dos trabalhadores no capitalismo}

A introdução de inovações tecnológicas e organizacionais no processo produtivo é uma constante no modo de produção capitalista. Marx (1988) foi um dos primeiros pensadores a tratar esses elementos como endógenos ao processo de acumulação desse modo de produção, analisando-os no contexto da dinâmica da luta entre as classes sociais do capitalismo. Cumpre ressaltar que a teoria de Marx sobre o processo de trabalho está intimamente relacionada com sua teoria das classes sociais, sendo o conceito de classe construído a partir das formas de apropriação do trabalho excedente que, por sua vez, relaciona-se com as formas de propriedade, ou seja, a propriedade ou não dos meios de produção.

Segundo Marx (1988), o processo de trabalho no capitalismo consiste em um processo de valorização do capital, sendo o seu objetivo principal o aumento da produção da mais valia. A questão que se coloca para o capital é a de como aumentar a produção da mais valia independentemente do prolongamento da jornada de trabalho. Esse processo torna-se possível através da redução do

\footnotetext{
1 Com o intuito de garantir o sigilo à empresa e aos entrevistados, serão utilizados codinomes. 2 A pesquisa se encontra em uma nova etapa, que visa problematizar os impactos da reestruturação produtiva no sindicato dos trabalhadores de fumo. Apoio Fapemig. Período: 2008-2010.
} 
tempo de trabalho necessário - a parte do tempo que o trabalhador utiliza para si mesmo - e aumento do mais trabalho, que corresponde ao tempo de trabalho para o capitalista. Dessa forma o capital aumenta a força produtiva do trabalho "[...] mediante mudanças nos meios de trabalho ou nos métodos de trabalho ou em ambos.” (MARX, 1988: 238) e o processo de valorização do capital passa a se estabelecer através da mais valia relativa.

Portanto, o capital realiza a mais valia relativa através de um processo de mudanças nos meios de produção e métodos de organização do trabalho por meio da aplicação da tecnologia, que por sua vez, reduz o valor da mercadoria e da força de trabalho. Há um estímulo individual do capitalista para a redução do tempo de trabalho necessário que é o barateamento da mercadoria devido à concorrência dos demais capitalistas. A concorrência, assim, impele o capitalista a transformar as condições técnicas e sociais do processo de trabalho através da apropriação do saber dos trabalhadores (Ibidem). Nesse sentido,

[...] a mesma lei da determinação do valor pelo tempo de trabalho que se fez sentir ao capitalista com o novo método na forma de ter que vender sua mercadoria abaixo de seu valor social, impele seus competidores, como lei coercitiva da concorrência, a aplicar o novo modo de produção (Ibidem: 241).

$\mathrm{O}$ capitalista que introduz as mudanças no processo produtivo tem a possibilidade de apropriar-se de maior parte da jornada de trabalho para o mais trabalho do que os demais capitalistas que ainda não introduziram a mudança. Entretanto, essa mais valia extra, obtida quando o capitalista individual consegue obter maior lucro que os demais, desaparece à medida que a mudança se generaliza na economia capitalista (Ibidem). Assim, o aumento da força produtiva do trabalho estende-se pelos ramos da produção, por um lado, barateando a mercadoria e, por outro lado, reduzindo o valor da força de trabalho. Nas palavras de Marx (1988), “[...] é impulso imanente e tendência constante do capital aumentar a força produtiva do trabalho para baratear a mercadoria e, mediante o barateamento da mercadoria, baratear o próprio trabalhador." (Ibidem: 242).

Há, dessa forma, um estímulo intrínseco ao modo de produção capitalista que faz com que o capitalista queira investir em novas técnicas de produção e organização do trabalho, alterando as forças produtivas. De acordo com Marx (1988), o que distingue as diferentes épocas econômicas: “[...] não é que se faz, 
mas como, com que meios de trabalho se faz. Os meios de trabalho não são só medidores do grau de desenvolvimento da força de trabalho humana, mas também indicadores das condições sociais nas quais se trabalha” (Ibidem: 144).

Ao analisar a cooperação, a manufatura e a grande indústria partindo da experiência inglesa, Marx demonstra como modo de produção capitalista vai ajustando, historicamente, as forças produtivas do processo produtivo à sua determinação através da apropriação e subjunção do saber do trabalhador. $\mathrm{O}$ processo de produção capitalista se iniciou quando os trabalhadores, reunidos sob a coordenação de um único capital, passaram a produzir a mesma espécie de mercadoria, fornecendo um grande número de produtos para a troca no mercado. Esse estágio, onde os trabalhadores são reunidos sob um mesmo espaço físico, produzindo uma mercadoria que já não mais lhes pertence, porém mantendo sob seu domínio as técnicas de produção Marx (1988) denominou de cooperação simples.

Nessa fase teve início a subordinação formal do trabalho ao capital posto que os trabalhadores não possuíam mais os instrumentos de trabalho, embora fossem ainda detentores das técnicas produtivas. Se por um lado não houve intervenção do capitalista na forma técnica de como produzir, por outro ocorreram as primeiras mudanças "objetivas" no processo de trabalho uma vez que houve aumento da escala de produção, redução do valor total da mercadoria e redução do valor da força de (Ibidem). Segundo Marx (1988), a cooperação consistia em uma forma de organização do trabalho que existia deste a Antigüidade não sendo, portanto, específica do capitalismo. A especificidade do modo de produção capitalista foi ter reunido "[...] trabalhadores livres assalariados em um mesmo processo de trabalho [...]. É a primeira modificação que o processo de trabalho real experimenta pela sua subordinação ao capital" (Ibidem: 265).

Outra especificidade do modo de produção capitalista foi ter atribuído à função de direção um aspecto que se diferenciava daquele meramente técnico, de coordenação do trabalho, implicando em um duplo conteúdo. Esse duplo conteúdo ocorre em decorrência da dupla natureza do processo de dirigir, que constitui, ao mesmo tempo, processo de trabalho social, objetivando a produção de valores de uso e processo de produção de mais valia (MARX, 1988). Cumpre destacar que no processo de trabalho capitalista o trabalhador individual não 
põe em funcionamento os meios de produção da sociedade. Sem o controle do capitalista, que é um momento tecnicamente indispensável do processo de trabalho, este não possui adequação necessária para que seja trabalho social, isto é, trabalho utilizado pela sociedade e reconhecido por ela. Sendo assim, a adequação própria à produção capitalista implica em cooperação e divisão das funções de controle e execução. O capitalista exerce, portanto, uma dupla função quais sejam: como explorador da força de trabalho e como organizador da produção (BRAVERMAN, 1977).

A manufatura, segunda etapa da evolução das forças capitalistas de produção, teve origem na cooperação. Marx (1988) caracterizou duas formas possíveis para seu desenvolvimento. A primeira quando diferentes ofícios passaram a ser reunidos sob a direção de um mesmo capitalista, visando à produção de um único produto. A segunda alternativa ocorreu quando o capital "decompôs" em tarefas distintas um único ofício. Entretanto, por quaisquer dos dois caminhos pelo quais a manufatura pôde ser desenvolvida, o objetivo do capital foi o mesmo, qual seja: a divisão ao máximo do trabalho vivo, fazendo com que cada trabalhador executasse apenas uma parte da totalidade da produção, visando um crescimento maior da produção em relação ao que era produzido quando cada trabalhador executava a totalidade do trabalho. A cooperação também se fez presente nessa fase, porém, na conexão das tarefas parcializadas. Em outras palavras, a partir desse momento, o trabalhador só poderá exercer seu ofício em cooperação, sendo impossível a reversão ao trabalho artesanal.

Durante o período manufatureiro, houve uma mudança qualitativa tanto na natureza do trabalho, quanto nos instrumentos de trabalho. No primeiro caso, deve-se destacar a separação do trabalho entre qualificado e desqualificado. Os custos e o tempo de aprendizagem do trabalhador parcial, mesmo qualificado, tornaram-se reduzidos, comparando-se com o trabalho artesanal, sendo praticamente inexistentes tratando-se de um trabalho desqualificado. No que se refere aos instrumentos de trabalho, vale destacar o seu aperfeiçoamento e sua diversificação, criando-se as condições para o desenvolvimento da maquinaria. Cabe destacar ainda que em ambos os casos houve a redução do valor da força de trabalho e conseqüente valorização do capital. Entretanto, a manufatura ainda impunha limites à reprodução do 
capital uma vez que sua base técnica continua sendo o próprio trabalho vivo. $\mathrm{O}$ aumento da produtividade era restringido pelo fato do trabalho manter-se como trabalho manual e ainda deter os conhecimentos e as habilidades necessárias à produção e, portanto, fora do controle do capital (MARX, 1988). Assim, a manufatura criou as condições para o desenvolvimento da maquinaria pela sua própria natureza, fundada no trabalho humano, pela grande especialização das ferramentas e pela sistemática divisão do trabalho, sendo desenvolvidos, portanto, os mecanismos técnicos e científicos para a materialização da subordinação real do trabalho ao capital.

$\mathrm{Na}$ fábrica, com a introdução da maquinaria, o processo de produção constituiu resultado direto da aplicação científica e tecnológica sobre como produzir. A máquina, que no início do século XIX tinha por princípio operar várias ferramentas ao mesmo tempo, significou o início do processo de automação industrial, cuja tendência apontada por Marx era de tornar-se cada vez mais intenso. Nesse período, o capital torna-se independente das habilidades do trabalho vivo. O ritmo do processo e as habilidades requeridas passam a ser definidas pela máquina, havendo uma perda significativa de conteúdo do trabalho, concomitantemente a um processo de intensificação do trabalho. É nesse momento que a subordinação do trabalho vivo ao trabalho morto torna-se real.

Marx (1988) considerou o conceito de controle do trabalho como central para o processo de industrialização: foi o modo pelo qual o trabalho foi subordinado ao capital. Coube a gerência, atividade primeiramente exercida pelo próprio capitalista e, posteriormente por um conjunto diferenciado de trabalhadores, a tarefa de exercê-lo. O controle como prática torna-se um componente necessário às relações capitalistas de produção na medida em que os trabalhadores não fornecem totalmente sua capacidade de trabalho, mas a retém por meio da responsabilidade de concepção e execução das tarefas, procurando assegurar o controle sobre o processo produtivo. Sob essas condições, os gerentes tentam assegurar todo o potencial do poder do trabalho, visando à garantia e o crescimento da produtividade no processo.

De acordo com Braverman (1977), a gerência busca assegurar o seu controle, primeiro determinando as tarefas individuais e depois através da direção de todo o dia de trabalho para a certeza de que as tarefas serão 
cumpridas. A legitimidade da gerência se assenta no discurso ideológico da aplicação científica e imparcial dos princípios de eficiência. No entanto, o autor mostrou em seu trabalho, a despeito da retórica da eficiência científica, como o taylorismo se torna um projeto ideológico de dominação com o objetivo de assegurar a subordinação real do trabalho. Assim, o controle do trabalho se faz necessário porque ele garante o caminho da produtividade, inibindo os tempos improdutivos para o capital, apropriando-se do conhecimento do trabalhador e, portanto, garantindo a sua acumulação.

É exatamente porque o capital não pode eliminar o trabalho vivo do processo de criação de valores que necessita aumentar a utilização e a produtividade do trabalho. O que se observa durante essa nova fase de reestruturação do capital é a redução do tempo de trabalho físico e manual direto, característico da fase de acumulação taylorista-fordista, combinada ao crescimento do trabalho multifuncional, flexível e participativo, elementos centrais do toyotismo. Sendo assim, a condição para que o sistema produtivo do capital se mantenha é a integração entre trabalho vivo e trabalho morto (ANTUNES, 2000).

É importante destacar que em determinados momentos históricos um conjunto de mudanças, envolvendo novas práticas de organização e controle do processo de trabalho torna-se paradigmática, em função das mudanças que assinala nas práticas industriais anteriores. Essas mudanças, resultado da dinâmica das relações de classe, acabam por promover um grande salto quantitativo e qualitativo no processo de acumulação capitalista, traçando assim novos contornos para a luta de classes, implicando em transformações significativas na estrutura social, política e cultural na sociedade determinada pela lógica do capital. Pode-se afirmar que o processo de introdução da maquinaria descrito por Marx foi um desses momentos, assim como posteriormente $\mathrm{o}$ foi $\mathrm{o}$ processo de racionalização taylorista-fordista na indústria automotiva e desde as duas últimas décadas do século XX estão sendo as formas flexíveis de acumulação. No entanto, há na literatura autores que argumentam sobre a preponderância da ciência e da tecnologia como forças produtivas nas sociedades contemporâneas em detrimento do trabalho vivo, enfatizando, portanto, o aspecto da inovação e da difusão técnica nesse amplo processo de transformações. 
Para esses autores, a difusão de uma inovação tecnológica está associada ao potencial que essa tecnologia tem de transformar os setores da economia, assim como induzir à formação de novos setores, levando ao desenvolvimento de um novo paradigma técnico-econômico mediante combinação de processos de inovação (FREEMAN; PEREZ, 1988; PEREZ, 2002), quais sejam:

(a) inovações incrementais: aquelas que ocorrem sem resultado direto de uma pesquisa formal, mas através de pequenas mudanças no processo produtivo. Seus efeitos estão mais relacionados ao crescimento da produtividade;

(b) inovações radicais: aquelas cujo resultado está diretamente relacionado à pesquisa e atividades de desenvolvimento em empresa e/ou universidades e laboratórios governamentais. São mudanças totalmente novas que ocorrem no intervalo de grandes períodos.

(c) novos sistemas tecnológicos: inovações incrementais e radicais articuladas que têm um grande impacto na economia.

Segundo os autores, a combinação dos processos de inovação e a formação de um novo sistema ou paradigma tecnológico é relativamente rara na economia, consistindo em um novo ciclo de desenvolvimento3.

A propensão de o sistema inovar ocorre em períodos de crescimento. Nesses períodos há o desenvolvimento da onda primária, onde ocorre a inovação, desenvolvendo-se na onda secundária os efeitos multiplicadores, isto é, o processo de difusão da inovação, dando início a um período de crise econômica e social. Nesse sentido, a inovação consiste, por um lado, no início de uma crise e, por outro lado, na sua recuperação à medida que os setores industriais, bem como as estruturas sócio-institucionais, vão adequando-se às inovações (FREEMAN; PEREZ, 1988). Nas palavras dos autores:

É evidente que este é um período de transição caracterizado por uma profunda mudança estrutural na economia que requer transformações igualmente profundas nas instituições sociais. $O$ quadro de uma recessão prolongada tende a indicar o crescente grau da má combinação entre o subsistema técnico-econômico e a velha estrutura sócio-institucional (FREEMAN; PEREZ, 1988: 59).

Freeman e Perez (1988) e Perez (2002) apontam que no paradigma técnico-econômico devem estar presentes fatores chaves, isto é, um tipo de

\footnotetext{
3 Os autores fundam sua análise na Teoria dos Ciclos de Kondratiev-Schumpeter. Consultar N. Rosenberg e C. R. Frischtak (1983).
} 
insumo particular que deve cumprir três características básicas para se difundir:

(a) Custos reduzidos e decrescentes;

(b) Disponibilidade de fornecimento por longos períodos, condição essencial para decisões de investimentos;

(c) Potencial para uso ou incorporação em novos processos e produtos, reduzindo custos e alterando qualitativamente o sistema econômico.

Para esses autores chamados neoschumpterianos, essa combinação de fatores se deu com a utilização da energia elétrica e do petróleo, possibilitando a generalização da produção em massa de base técnica eletromecânica. $\mathrm{O}$ regime tecnológico que predominou no pós-guerra, o taylorismo-fordismo, baseou-se nos baixos custos do petróleo e intensiva utilização de energia de materiais nos setores econômicos, particularmente o setor automotivo. Do ponto de vista da organização, em nível da planta difundiu-se a linha de montagem e, em nível da empresa difundiu-se a grande corporação, incluindo departamentos de pesquisa e desenvolvimento (P\&D), e mercados oligopolizados. Quanto à organização do trabalho, esse regime requeria grande número de trabalhadores pouco qualificados - o operário-massa, realizando tarefas parcelares e desprovidas de conteúdo e sentido para o trabalhador.

A partir do final da década de 1970, as economias capitalistas avançadas iniciaram uma fase de transição para um novo paradigma tecnológico posto que a combinação dos fatores expostos anteriormente passou a ser encontrada na nova tecnologia de base microeletrônica ou de informação. A nova tecnologia, fundada na flexibilidade, envolve vários fatores, entre eles:

(a) Uma nova prática de organização em nível da firma e da planta;

(b) Nova concepção da inovação de processos, produtos e serviços com a expansão de ramos e novos setores de produção;

(c) Novas formas de distribuição e consumo;

(d) Novas localizações para investimentos nacionais e internacionais com tendência à concentração de grandes firmas e a diversificação de ramos de produção.

No que se refere ao trabalho, destaca-se a formação de um mercado de trabalho mais heterogêneo e qualificado, com exigências de maiores níveis de escolaridade e de novas habilidades. Essas mudanças afetam qualitativa e quantitativamente o trabalho e sua organização no processo produtivo. O novo 
paradigma técnico-econômico desenvolve-se no velho paradigma, emergindo gradualmente à medida que seus elementos ou fatores-chaves tenham satisfeito as três condições básicas já mencionadas. O período de nascimento de um novo paradigma é caracterizado pelos autores como de transição, no qual as mudanças econômicas requerem mudanças na estrutura institucional que, até então, adequava e regulava as relações sociais, econômicas e políticas no velho paradigma. De acordo com os autores:

[...] a formação de um novo sistema tecnológico têm conseqüências para todos os setores da economia e sua difusão é acompanhada de uma crise estrutural de ajustamento em que mudanças sócio políticas, em âmbito institucional, são necessárias para a formação de um novo paradigma de regulação de uma nova ordem. O conjunto dessas mudanças leva à formação de um paradigma técnicoeconômico ou revolução tecnológica que envolve todos os setores da economia, destruindo alguns e criando outros, bem como mudanças nas instituições sociais e políticas (FREEMAN; PEREZ, 1988: 38).

É interessante notar que os autores atribuem uma posição de independência e autonomia da técnica sobre as relações sócio-institucionais, conferindo um caráter determinista à análise da explicação do processo de transformação social (HOLLOWAY; PELÁEZ, 1998; MARTINS, 2005). A relação entre mudança técnica e "ajuste" sócio-institucional confere uma posição de subordinação desta última à primeira, tornando o conjunto das relações sócio-culturais e de classe dependentes a atributos técnicos quando, em realidade, a técnica insere-se no contexto mais amplo do modo de produção capitalista e sua forma de acumulação.

Ao considerar a problemática do desenvolvimento tecnológico no capitalismo, Mandel (1985) argumenta que as escolhas sobre determinadas técnicas em detrimento de outras são realizadas por razões de lucratividade pelos ramos específicos da indústria, ou melhor, pelas empresas líderes naqueles ramos, dependendo, portanto, das relações de poder no seio da sociedade capitalista. Portanto, o grande limite do pensamento dos autores discutidos - e pode-se estender essa análise aos demais neoschumpeterianos está no fato de não articularem o conceito de paradigma tecnológico e mesmo da mudança técnica à lei do valor, que é o que fundamenta historicamente o dinamismo tecnológico na ordem do capital. Dessa forma, o conhecimento social gerado pelo progresso científico tem seu objetivo restringido pela lógica do capital ao mesmo tempo em que ocorre a apropriação desigual dos resultados e benefícios da ciência e da tecnologia, bem como do aumento da 
produtividade do trabalho social (ANTUNES, 2000 e 2006).

Entendemos assim que a inovação técnica e/ou organizacional deve ser compreendida no âmbito das diferentes práticas sociais que, por sua vez, são produto das relações de classe na luta pelo controle social do trabalho no capitalismo. Ela está inserida na dinâmica da luta de classes, sendo variável política e de controle social (HOLLOWAY; PELÁEZ, 1998; PREVITALLI, 2005; MARTINS, 2005). Assim, a necessidade da constante reorganização do processo produtivo ocorre justamente como necessidade de combater a resistência dos trabalhadores ao controle e à racionalização.

Braverman (1977) argumenta que o meio de impedir o controle do processo de trabalho pelos trabalhadores foi através da dissociação entre concepção e execução, isto é, entre trabalho intelectual e trabalho manual. A conseqüência imediata dessa dissociação foi a desqualificação do trabalhador, dada a nova natureza que o trabalho adquiriu, reduzido a tarefas simplificadas e rotineiras, cada vez mais especializadas e sem conteúdo. O taylorismo-fordismo configurou-se na expropriação do saber operário e a sua concentração nas mãos da gerência administrativa. Esta, por sua vez, racionalizou a produção, estabelecendo "o melhor caminho" para a realização do trabalho.

O espaço interno da fábrica foi reorganizado, fixando o trabalhador em um ponto, o posto de trabalho, realizando os mesmos movimentos e utilizando as mesmas ferramentas. Os trabalhadores perderam, não somente o controle e a capacidade de decisão que possuíam sobre o processo de trabalho, mas também passaram a ser colocados sob o domínio de uma estrutura administrativa fortemente hierarquizada (BRAVERMAN, 1977).

Apesar do movimento de racionalização, implicando na desqualificação do conteúdo das tarefas no trabalho parcelar, as habilidades e o ritmo do mesmo ainda dependiam do trabalhador, posto que o trabalho vivo permanecia como a base do processo produtivo, levando ao desenvolvimento de um conjunto de práticas cotidianas no chão de fábrica, envolvendo aceitação e resistência ao controle do trabalho (BURAWOY, 1978).

O taylorismo-fordismo envolveu, com variações dependendo das condições históricas, sociais e culturais onde foi vivenciado, um conjunto de práticas de político-institucionais e de controle do trabalho, bem como de formas de intervenção e resistência classe trabalhadora de 1930 até 1960, quando começou 
a apresentar sinais de esgotamento (AGLIETTA, 1979). Como resposta a crise, o capital iniciou, ao longo das décadas de 1980 e 1990, um amplo processo de reestruturação que envolveu a introdução de inovações técnicas e/ou organizacionais no processo de trabalho, visando assegurar o controle sobre o mesmo. A expressão mais evidente dessas mudanças foi o advento das formas toyotistas ou do chamado "modelo japonês" de organização do processo produtivo que se tornaram o novo receituário de eficiência e produtividade a ser seguido (ALVES, 2000; ANTUNES, 2000 e 2006).

Nesse sentido, o que se observa a partir das duas últimas décadas do século XX é a construção de uma nova forma de racionalização do processo de trabalho que potencializa o controle e a vigilância no local de trabalho (SEWELL; WILKINSON, 1992; SEWELL; 1998). Essa racionalização tem imposto aos trabalhadores um intenso e cuidadoso monitoramento por meio das análises constantes de índices de produtividade, de desempenho, de satisfação, entre outras, sendo apresentada sob a celebração da qualificação e sua maior inserção intelectual no trabalho, como poderemos observar na discussão do estudo de caso a seguir.

\section{A pesquisa: reestruturação produtiva e organização do trabalho no setor de fumo em Uberlândia/MG}

No estudo realizado no setor de fumo buscamos discutir a introdução do trabalho em equipes na indústria de cigarros, verificando a hipótese das equipes de trabalho como uma nova forma de intensificação e flexibilização do trabalho, atrelada às novas exigências de qualificação do trabalhador, bem como a configuração de uma nova relação interfirmas ao longo da cadeia produtiva do setor.

Segundo a Associação Brasileira da Indústria do Fumo (Abifumo), existem aproximadamente 35 indústrias de fumo no Brasil, 16 delas associadas à entidade. Na década de 1990 o país era líder no ranking mundial de exportação de tabaco e o terceiro na produção mundial. O país produz anualmente 550 mil toneladas de fumo; destas, 435 mil toneladas vão para o mercado externo, restando 115 mil toneladas para consumo interno. Em volume exportado atinge US\$ 1 bilhão/ano, equivalente a $2 \%$ das exportações brasileiras. O setor possui ainda significativo potencial de geração de empregos, aproximadamente 2,5 milhões 
de empregos, sendo 800 mil de forma direta. $4 \mathrm{Na}$ safra de 2005/o6 foram empregados 2.450.000 trabalhadores, sendo $35.0000(1,4 \%)$ trabalhadores diretos com carteira assinada (registrados) na indústria. A grande maioria dos empregos diretos no setor se encontra na lavoura, cerca de $965.000(39,4 \%) .5$

A fumicultura caracteriza-se por ser uma agroindústria, envolvendo de forma coordenada a agricultura e a indústria e, seguindo as tendências gerais de reestruturação produtiva no Brasil (ABREU, et al 2000; PREVITALLI, 2006a e 2006b), apresenta mudanças em suas formas de organização interna e nas relações interfirmas ao longo de sua cadeia produtiva. Ao longo da pesquisa, verificamos o surgimento de novas formas de flexibilização do trabalho observadas tanto nas primeiras relações da cadeia produtiva, até as relações de produção de chão de fábrica na manufatura do fumo. Cumpre dizer que as novas práticas da Fábrica Uberlândia vêm desafiando de modo significativo a ação sindical local que no ramo de fabricação de cigarros, a Fábrica Uberlândia constitui um dos cinco maiores grupos econômicos brasileiros, sendo subsidiária do grupo British American Tobacco, o segundo maior do mundo no mercado de tabaco, operando em aproximadamente 180 países. Ela foi fundada em 25 de abril de 1903 e atua em toda a cadeia produtiva, ou seja, fumicultura, fabricação e distribuição do produto cigarro tendo, portanto, um nível bastante acentuado de verticalização naquilo que define como seu core business e terceirizando atividades consideradas complementares. Vale dizer que a empresa gera aproximadamente 5 mil empregos diretos e 380 mil empregos indiretos ao longo da cadeia produtiva. Em 2003 teve um faturamento de US\$ 6,8 bilhões. Ela detém $60,4 \%$ de participação no mercado total brasileiro comercializando 78 bilhões de unidades de cigarros em 2006. É responsável pelo processamento de 3,6\% da produção mundial de fumo, posicionando-se entre os três maiores exportadores do Brasil, com cerca de 5,6\% do comércio mundial, vendendo para aproximadamente 50 países dos 5 continentes.

A unidade produtiva localizada em Uberlândia foi fundada em 28 de fevereiro de 1978. Atualmente produz aproximadamente 65 bilhões de cigarros/ano, sendo a maior fábrica do segmento em toda a América Latina. Sua localização é estratégica, no Triângulo Mineiro, estando entre os maiores

4 Informação obtida no site: <http//www.istoe/dinheiro>. Maio, 2002.

5 Dados do Instituto Brasileiro de Geografia e Estatística - IBGE (2005). 
mercados atacadistas brasileiros. A partir de 1985 a produção das unidades produtivas da empresa no Brasil, localizadas nos estados do Rio de Janeiro, Porto Alegre, São Paulo, Recife, Belo Horizonte e Salvador foi sendo gradativamente assumida pela Fábrica Uberlândia. A centralização da produção de cigarros, ao efetivar-se, representou o fechamento de $90 \%$ das fábricas e a dispensa de trabalhadores pelo Brasil. A escolha de Uberlândia, em Minas Gerais, para a concentração da produção deveu-se primordialmente a dois fatores: localização estratégica, sendo a cidade de Uberlândia um pólo de referência comercial e industrial e a baixa organização do movimento sindical na região, fortemente combativo nas décadas de 1970 e 1980.

\section{Organização e controle do processo de trabalho}

A folha de fumo que dá início ao processo produtivo é separada nas usinas -localizadas na região Sul- de modo que o processamento (da usina) transforma as folhas em fardos ${ }^{6}$ que chegam à fábrica, distinguidos em Fumo Virgínia (seco em estufa) e Fumo Burley (seco ao ar livre). O processo de trabalho na Fábrica Uberlândia é composto em fase inicial por quatro linhas de produção em função da variação das matérias-primas, quais sejam: a) fumo normal, b) fumo de torrefação, c) talo longo e d) talo curto que, ao final do processo, sofrem uma mixagem constituindo a base das diferentes marcas de cigarro. Todo o processamento do fumo é marcado pelo constante controle de umidade e temperatura. O rígido controle das variações de umidade e temperatura tem como principal objetivo evitar que a matéria-prima seja desperdiçada ou não atinja as condições ideais de processamento, ocasionando maior desgaste das máquinas e estragos financeiros.

A variação de custo dos cigarros produzidos decorre da quantidade da principal matéria-prima utilizada (folha de fumo). Dessa forma, quanto mais mixado o cigarro, menor o preço final, pois as adições da mixagem (talo, essências, extratos) possuem menores custos. A produção semanal é determinada pela célula de produção, que define marca e quantidade de cigarros produzidos. Esse processo decisório envolve questões de ordem externa, como a demanda do mercado, por exemplo. Encontram-se nas células

\footnotetext{
6 Cada fardo tem $200 \mathrm{~kg}$.
} 
analistas de processos, técnicos eletrônicos, e coordenador.

A partir de 2000 a Fábrica Uberlândia intensificou o processo de reestruturação produtiva, implementando programas que visam assegurar a qualidade do processo e auferir maior flexibilidade. O layout passou a funcionar de maneira celular, organizando-se em mini-fábricas que, por sua vez, foi estruturado em quatro comitês, quais sejam: a) produção, b) Recursos Humanos, c) Qualidade e d) Custos. Cada comitê realiza uma série de atividades, relacionadas ao funcionamento e administração das mini-fábricas e corporativamente ao funcionamento geral da Fábrica. Os trabalhadores da produção passaram a trabalhar em equipes multifuncionais.

Nesse aspecto, as mudanças observadas resultam em maior sobrecarga para os trabalhadores de chão de fábrica, já que estes passaram a assumir as tarefas antes tidas como gerenciais, sem a contrapartida salarial. O trabalho organizado em equipes atinge, desde a organização de horários de folgas até a resolução de problemas na produção. Além do mais, a produção em células exige maior polivalência do trabalhador, já que as máquinas são agrupadas por etapas de produção e não por semelhanças de funcionalidade. Dessa forma, resta à nova gerência, aprimorar a qualidade do processo decisório, fomentar a iniciativa (incitar a criatividade do trabalhador), captar e avaliar o feedback, analisar incidentes críticos junto às mini-fábricas e motivar as equipes. Um dos principais papéis da gerência é sua atuação direta no estabelecimento de metas dentro das mini-fábricas e no desenvolvimento de carreiras de seus empregados.

Segundo entrevista7 concedida por um gerente de uma mini-fábrica visitada, a partir desse modelo de gestão os trabalhadores passaram a receber total autonomia para a tomada de decisões operacionais e de planejamento de suas atividades. De acordo com projeto AUGE, ${ }^{8}$ esse modelo de organização, quando atingido na sua plenitude, afirma que as equipes atuarão de forma autônoma como resultante de um processo evolutivo das formas de organização do processo de trabalho. As equipes passarão a ser mais responsáveis, flexíveis e compromissadas com seus objetivos de produção conferindo as atividades maior produtividade. No entanto, observamos que as regras são pré-

\footnotetext{
7 Entrevista realizada em 10/03/2007.

8 Nome do projeto que implementou o trabalho em equipes a partir de 2002.
} 
estabelecidas, delimitando de forma significativa o campo de ações e competências dos trabalhadores envolvidos no projeto. A Figura 1 sugere o modelo de organização em equipes a ser alcançado pela empresa:

Figura 1: Evolução do Grau de Autonomia das Equipes de Trabalho.

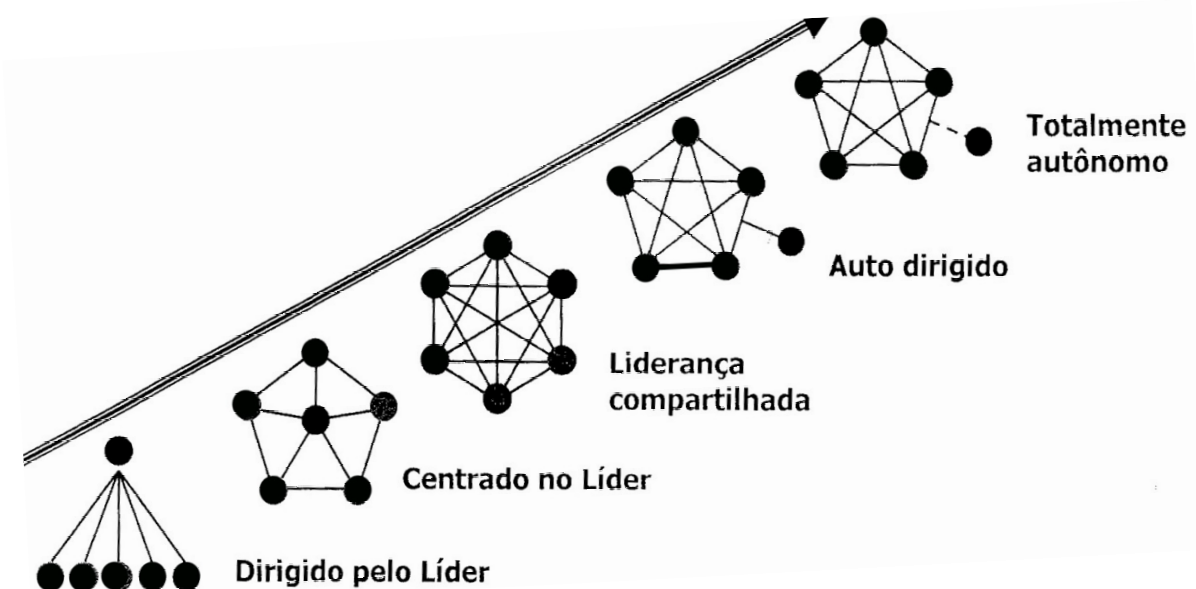

Fonte: Elaborada a partir de documento da Fábrica Uberlândia.

Para se atingir o último estágio evolutivo do modelo, o treinamento sugere que os trabalhadores estejam organizados sob os mesmos propósitos e comprometidos com o alcance das metas, adquirindo assim a vantagem da sinergia. O incentivo a comunicação nesse estágio é fundamental, uma vez que promove a confiança e o encorajamento mútuo para a resolução de problemas. As organizações têm seu foco na livre competição e na idéia de que os melhores vencerão, aplicando esses conceitos no local de trabalho, incentivando a busca do sucesso individual, reduzindo laços de solidariedade entre os trabalhadores e assim, dificultando estratégias de resistência coletivas.

Observamos ainda na pesquisa a maximização do controle dos tempos e movimentos dos trabalhadores envolvidos nas equipes semi-autônomas, numa clara permanência de princípios tayloristas-fordistas. Através de reuniões relâmpagos e de constantes treinamentos durante o turno de trabalho, enfatizase a necessidade de participação, envolvimento e dedicação durante a produção de cigarros, buscando-se reduzir as porosidades deste processo. Convém destacar que as reuniões relâmpagos têm o objetivo de desestruturar as reuniões espontâneas dos trabalhadores que ocorrem sem o controle e supervisão da 
gerência.

Dessa forma, é possível observar que a reestruturação no setor está implicando na adoção de novos padrões de organização de organização e controle voltados fundamentalmente para a captação da subjetividade do trabalhador, no sentido de buscar seu comprometimento e afrouxar laços de sociabilidade no chão-de-fábrica. As equipes também promovem a participação do trabalhador criando mecanismos de sugestões de idéias e proposições de projetos sobre o sistema produtivo no dia-a-dia no local de trabalho. Permite-se, no discurso empresarial, a possibilidade de trabalhadores, comissões de fábrica e o movimento sindical intervirem na dinâmica da introdução das novas formas organizacionais do processo de produção.

Esse novo modelo de gestão garante aumento de produtividade e benefícios para empresa, a partir da intensificação do controle sobre processo de trabalho. Utilizando-se dessas novas formas de controle a Fábrica Uberlândia potencializa elementos essenciais para promover e assegurar a motivação e envolvimento do trabalhador para com os objetivos da própria empresa. A cultura organizacional conseguida através das ideologias de participação e comprometimento com o crescimento da empresa é uma das formas de dominação e controle utilizadas, pois encontra sua legitimação nos valores $a$ priori transmitidos e posteriormente assimilados pelos trabalhadores.

O incentivo à democratização das informações sob a roupagem de valorização do conhecimento e a possibilidade de bom uso e maior eficiência a partir das mesmas, permite que haja transparência no processo de trabalho, e que, quaisquer mudanças nas etapas do mesmo não permaneçam fora do controle gerencial. Atrelado à democratização das informações ocorre a "valorização" da decisão das equipes, motivando os trabalhadores a se desempenharem cada vez, devido às recompensas em grande parte subjetivas que a própria ideologia promove. Assim, a competitividade é acentuada entre as próprias equipes e internamente a elas.

\section{Relações interfirmas}

A busca por novos padrões de competitividade para enfrentar a redução do mercado interno desembocou na formação de redes de subcontratação como 
alternativa de redução de custos. Devido aos obstáculos enfrentados pelo setor de fumo, tais como: pirataria, proibição de merchandising, redução do número de fumantes, campanhas contra o tabagismo, uma das estratégias de competitividade que acompanha as mudanças ocorridas no chão de fábrica são as novas relações interfirmas. Nesse sentido, as relações interfirmas no setor se estabelecem entre as grandes empresas e os agricultores que cultivam o fumo na base da cadeia produtiva. Na região Sul, maior arranjo fumageiro do país, o "dinamismo gerencial" garante que desde o início da cadeia produtiva, os agricultores destinem a produção exclusivamente para os grandes conglomerados beneficiadores do fumo.

Atendendo a demanda das empresas, a organização das áreas cultivadas segue os padrões desenvolvidos pelas grandes multinacionais que operam na região Sul (arranjo produtivo Vale do Rio Pardo). Através dos contratos firmados entre agricultores e empresas, as relações estabelecidas visam maior controle sobre o processo produtivo e exigem maior qualidade do produto e da força de trabalho envolvida nesse processo.

Na zona rural o controle sobre a produção foi imposto aos agricultores até então autônomos no cultivo do fumo. A liberdade dos agricultores é condicionada ao atendimento dos interesses das multinacionais, implicando na subordinação formal dos produtores desde a primeira etapa da cadeia produtiva. Tal organização ganha força à medida que interesses imediatos tanto das empresas quanto dos agricultores são alcançados, perdendo de vista o que uma possível queda do setor pode ocasionar.

A subordinação dos agricultores dá-se também quanto à classificação do fumo. Por determinação da Portaria n. 526, de 20 de outubro de 1993, e Portaria n. 79, de 17 de março de 1994, ambas do antigo Ministério da Agricultura, do Abastecimento e da Reforma Agrária,9 as folhas de fumo curadas são classificadas em grupos, subgrupos, classes, subclasses, tipos e subtipos, de acordo com o preparo, apresentação e arrumação, posição das mesmas na planta, cor e qualidade. São dois grupos: a) Tabaco de Estufa, contendo mais de 48 classes do fumo e b) Tabaco de Galpão, com 29 categorias e18 classes do fumo comum. A classificação acaba por resultar em instrumento de controle e manipulação durante o processo de comercialização do fumo, já que são as

9 Atualmente denominado Ministério da Agricultura, Pecuária e Abastecimento - MAPA. 
próprias indústrias que definem os preços de cada variedade fazendo a classificação da safra.

Esse é um dos principais focos de exploração dos agricultores familiares e mecanismo central para o domínio econômico da cadeia produtiva por parte das transnacionais integradoras, pois é onde concretamente se define a distribuição de renda gerada na atividade e onde se opera a previsibilidade e a segurança da execução dos contratos de exportação do fumo, mantendo um número estimado de agricultores integrados por meio do endividamento programado. As indústrias, cientes da dimensão do débito de cada fumicultor, oscilam na classificação do fumo a cada ano, de forma a estabelecerem a renda média auferida pelo agricultor, impossibilitando-o, por vezes, de quitar as dívidas de seu "pedido" junto à integradora no período contratado.

Outro aspecto que remete as mudanças engendradas pelas empresas do setor é que a maior parte das consultorias prestadas é realizada por terceiros, servindo também como intermediários da relação entre os agricultores e as próprias multinacionais. Já o produtor se compromete a entregar um determinado volume de tabaco, com a qualidade e os custos definidos pela empresa compradora. Esse acordo acaba significando um controle da companhia sobre o agricultor, além de direitos exclusivos sobre a plantação.

Desde as novas relações interfirmas, que subordinam as relações de produção no início da cadeia, consolida-se nesse setor da economia a precariedade das relações de trabalho, expropriação e captação da subjetividade dos assalariados envolvidos nesse processo. Convém mencionar que, guardadas as particularidades dos ramos produtivos, essas características de subordinação e controle podem ser observadas em outros setores econômicos como o automotivo, envolvendo a empresa-mãe e pequenas firmas na base da cadeia produtiva (ABREU; et al, 2000; PREVITALLI, 2002).

Entendemos neste trabalho que o conhecimento social gerado pelo progresso técnico-científico tem seu objetivo restringido pela lógica do capital ao mesmo tempo em que ocorre uma apropriação desigual dos resultados e benefícios da ciência e da tecnologia, bem como do aumento da produtividade do trabalho social. A teoria do valor reconhece o papel crescente da ciência, mas ressalta que a mesma encontra-se tolhida em seu desenvolvimento pela base material das relações entre capital e trabalho, a qual se encontra submetida. 


\section{Considerações finais}

Há na literatura a concepção segundo a qual as inovações tecnológicas e/ou organizacionais associadas às tecnologias de informação e ao trabalho em equipes possibilitam a oportunidade de ruptura da separação entre concepção e execução do trabalho, bem como do trabalho parcelar presentes na organização taylorista-fordista. Assim, tais inovações seriam mais eficientes e racionais para o desempenho do processo produtivo e para os trabalhadores, pois estariam possibilitando a recuperação da inteligência do trabalhador no local de trabalho e, ao mesmo tempo, garantindo maior produtividade para o capital.

Entretanto, evidenciamos em nossa pesquisa que tem havido uma limitada reintegração entre concepção e execução no âmbito do trabalho em equipes, havendo uma autonomia meramente nominal das mesmas que devem continuamente aumentar a produtividade.

A "nova gerência" incentiva o comprometimento e participação do trabalhador de chão de fábrica na forma de sugestões e projetos sobre o sistema produtivo no dia-a-dia no local de trabalho. No âmbito do discurso empresarial, é colocada a possibilidade de trabalhadores, comissões de fábrica e o movimento sindical intervirem na dinâmica da introdução das novas formas organizacionais do processo de produção. No entanto, o que observamos é que a adoção de novos padrões de organização do trabalho está voltada, fundamentalmente, para a captação da subjetividade do trabalhador no sentido de buscar seu comprometimento e afrouxar laços de sociabilidade no chão-defábrica. Utilizando-se das novas formas de controle, fundadas particularmente no trabalho em grupos multifuncionais, são potencializados elementos essenciais para promover e assegurar a motivação e envolvimento do trabalhador para com os objetivos da própria empresa, estimulando-se a competitividade intra e inter equipes de trabalho.

As novas formas de organização e controle do trabalho trazem consigo ainda princípios do taylorismo, uma vez que está fundado no controle de tempos e movimentos do trabalhador. Porém, o controle e a expropriação do mais valor não ocorrem mais pela presença da figura despótica do chefe ou gerente de seção, mas através da vigilância eletrônica no interior dos grupos para o cumprimento das metas. A constante reorganização do local de trabalho é, portanto, resultado inevitável da dual e contraditória necessidade do capital 
de neutralizar a resistência ao controle e aumentar a produtividade.

Embora estejam presentes os mecanismos de resistência em função da relação dialética entre capital e trabalho, eles ainda não se apresentam coletivamente, restringindo-se ao âmbito da consciência individual, contingente. Vale ressaltar que as formas de resistência se mostram fortes quando se tornam coletivas ou fazem parte de movimentos coletivos. Nesse sentido, torna-se fundamental a reorganização do movimento sindical de forma a responder às novas exigências da dinâmica das relações de classe.

\section{Bibliografia}

ABREU, A. R. P.; et al (org). Produção Flexível e Novas Institucionalidades na América Latina. Rio de Janeiro: Editora da Universidade Federal do Rio de Janeiro, 2000.

AGLIETTA, M. A theory of capitalist regulation. London: New Left Books. 1979.

ALVES, G. O novo (e precário) mundo do trabalho: reestruturação produtiva e crise do sindicalismo. São Paulo: Boitempo, 2000.

ANTUNES, R. Os sentidos do trabalho. São Paulo: Boitempo, 2000.

. Riqueza e miséria do trabalho no Brasil. São Paulo: Boitempo, 2006.

BRAVERMAN, H. Trabalho e capital monopolista. Rio de Janeiro: Zahar, 1977.

BRESCIANI, L. P. O contrato da mudança: a inovação e os papéis dos trabalhadores na indústria brasileira de caminhões. Tese de Doutorado. Campinas: IG/UNICAMP, 2001.

BURAWOY, M. Toward a Marxist theory of the labour process: Braverman and beyond. IN: Politics and Society. v. 8, $\mathrm{n}^{0}$ 3-4, 1978, pp: 247-312.

FARIA, A. F.; PREVITALLI, F. S. Reestruturação Produtiva e Organização do Trabalho: a difusão tecnológica e a introdução do trabalho em grupos na Indústria de Fumo no Brasil". In: Anais do V Congresso Latinoamericano de Sociología del Trabajo. Montevideo. 18-20 de abril de 2007.

FREEMAN, C.; PEREZ, C. Structural crises of adjustment, business cycles and investment behaviour. IN: DOSI. G. et al (Eds). Technical change and economic theory. London: Pinter Publishes, 1988, pp: 39-66.

GALVÃO. A. Os novos desafios do sindicalismo no governo Lula. IN: Outubro. São Paulo, n. ${ }^{0}$ 14, 2006. pp.: 131-150.

HOLLOWAY, J; PELÁES, E. Aprendendo a curvar-se: pós-fordismo e determinismo tecnológico. IN: Outubro. São Paulo, vol.2, novembro, 1998, pp: 21- 29.

MANDEL, E. O capitalismo tardio. Col. Os Economistas. São Paulo: Abril Cultural. 1985 . 
MARTINS, C. E. Os ciclos longos e a conjuntura contemporânea”. IN: Margem Esquerda, São Paulo, nº6, Ed. Boitempo, 2005, pp: 77-96.

MARX, K. O Capital. Vol.1, Primeiro Livro, Tomo I, Col. Os Economistas. São Paulo: Nova Cultural. 1988.

PEREZ, C. Technological revolution and financial capital: the dynamics of bubbles and golden ages. Cheltenham: Elgar, 2002.

PREVITALLI, F. S. O caso Mercedes-Benz: ABC e Campinas. IN: ANTUNES, R. (Org). Riqueza e Miséria do Trabalho no Brasil. São Paulo: Boitempo, 2006 a, pp: $147-154$.

. Controle e resistência do trabalho na reestruturação produtiva do capital no setor automotivo. IN: Mediações, Londrina, v.1, $\mathrm{n}^{\mathrm{0}} 1, \mathrm{MC}$ Gráfica, 2006b, pp:125-146.

ROSENBERG, N; FRISCHTAK, C. R. Inovação Tecnológica e ciclos de Kondratiev. IN: Pesq. Plan. Econ. Rio de Janeiro, 13(3). Dez. 1983, pp: 675-706.

SEWELL, G. The discipline of teams: the control of team-based industrial work through electronic and peer surveillance. IN: Administrative Science Quarterly, 43(2), June, 1998, pp: 358-396.

SEWELL, G.; WILKINSON, B. Someone to watch over me: surveillance, discipline and the just-in-time labour process. IN: Sociology, vol.26 (2), May, 1992, pp: 271-289.

Colaboração recebida em 26/6/2008 e aprovada em 8/10/2008. 